\title{
TCOM AMERICA LATINA \\ Encontro Nacional da Associação Brasileira de Centros e Museus de Ciências (ABCMC)
}

\section{Lara Mucci Poenaru}

Objecto revisado (Conferência)

\section{Resumo}

Palavras-chave

\author{
Encontro nacional da Associação Brasileira de Centros e Museus de \\ CIÊNCIAS (ABCMC), \\ Museu do Amanhã, Rio de Janeiro, Brazil, 10-15 de Setembro de 2018
}

Realizado no segundo semestre de 2018, o $3^{\circ}$ Encontro Nacional da Associação Brasileira de Centros e Museus de Ciência (ABCMC), um dos mais expressivos encontros de centros e museus de ciência do país, colocou em pauta discussões atuais e relevantes para a área, como Agenda 2030; Inclusão e Acessibilidade; Sustentabilidade. Marcado pela recente tragédia que atingiu o Museu Nacional e levou à perda de grande parte de sua estrutura física e acervo, o evento reforçou a forte apreensão das instituições latino-americanas frente ao futuro cenário político, mas também trouxe diversos exemplos de iniciativas de divulgação científica bem sucedidas que trazem otimismo aos que atuam no setor.

Ciência cidadã; Popularização da ciência e da tecnologia; Divulgação científica nos países em desenvolvimento

https://doi.org/10.22323/3.01011001

Recebido em 19 de Setembro de 2018

Aceito em 26 de Setembro de 2018

Publicado em 21 de Novembro de 2018

O Encontro Nacional da Associação Brasileira de Centros e Museus de Ciências (ABCMC), evento bienal organizado pela mesma associação, teve sua terceira edição realizada no Museu do Amanhã, Rio de Janeiro, entre os dias 10 e 15 de setembro de 2018. Voltado para os profissionais (gestores, mediadores, técnicos, curadores) envolvidos no setor museal, pesquisadores da área, estudantes e demais interessados, o evento é uma das mais expressivas oportunidades de trocas de expertises, práticas e estudos entre aqueles que trabalham com museus, centros de ciência e divulgação científica no país. 
Sob o tema "Centros e Museus de Ciências nas sociedades em rede", o encontro mobilizou a apresentação de mais de 100 trabalhos - entre resultados de estudos, estudos em andamento e compartilhamento de experiências, - além de oficinas oferecidas por instituições parceiras, visitas técnicas a espaços científico-culturais da cidade, e mesas-redondas que discutiram temas emergentes para a área, como inclusão social e empoderamento; controvérsias, diversidade e diálogos; políticas públicas concernentes à C\&T; dentre outros.

A grande tônica do evento, porém, foi a mesa de abertura planejada em homenagem aos 200 anos do Museu Nacional, instituição científica mais antiga do país que, no início do mês, sofreu um grave incêndio que culminou com a destruição da maior parte de seu acervo e sua estrutura física. Prevista ainda antes da tragédia, a mesa-redonda foi marcada por uma forte comoção e profunda reflexão acerca das dificuldades enfrentadas pelas instituições públicas nacionais frente ao sucateamento desses espaços pela falta de políticas públicas e repasses financeiros condizentes com suas necessidades. Além disso, a abertura do evento foi finalizada com a homenagem e entrega de títulos de sócios honorários in memoriam aos pesquisadores de relevância da área que faleceram este ano, como Jorge Wargensberg e Ernst Wolfgang Hamburger.

As principais discussões empreendidas durante o evento podem ser divididas em três grandes tópicos: Inclusão e acessibilidade; Políticas públicas e sustentabilidade de museus; Ética e democracia para uma ciência cidadã. $O$ primeiro diz respeito à exclusão e aos autoritarismos dentro dos próprios museus que, ao selecionarem seu acervo e definirem o que tem valor e relevância neste, acabam por excluir uma gama de identidades coletivas e reforçar ainda mais as barreiras invisíveis frente a seus públicos. Nesse sentido, as provocações propostas pelos conferencistas convergiam para a ideia de que a divulgação científica é sempre uma ação política, uma tomada de posição sob uma ótica não neutra.

A questão da acessibilidade talvez seja a temática mais vigorosa dentre as discussões do evento, o que se refletiu no alto número de pesquisas apresentadas que tangenciavam o assunto. Viviane Sarraf (Universidade de São Paulo) explicou a importância de se discutir e trabalhar com medidas que visem à acessibilidade, uma vez que a deficiência não é uma tendência, mas uma situação permanente, que sempre vai existir, e é uma condição de todos nós. O segundo tópico, Políticas públicas e sustentabilidade de museus, ganhou ainda mais relevância devido à tragédia do Museu Nacional, que deixou evidente o "efeito montanha-russa", termo cunhado por Martha Cambre (diretora da Red de Popularización de la Ciencia y la Tecnología em América Latina y el Caribe, RedPop), que se refere à dependência de se associarem as ações museais às mudanças políticas, especialmente em países da América Latina. $\mathrm{O}$ marco legal que congela investimentos em educação no Brasil por 20 anos, aprovado no Brasil em 2017, e a medida provisória que extingue o Instituto Brasileiro de Museus (IBRAM), responsável pela gestão dos museus federais, foram alguns dos exemplos de políticas públicas que minam a sustentabilidade de museus.

Sob a mesma ótica, foi defendida e aprovada na sessão plenária do evento a proposta elaborada por Martha Marandino (Universidade de São Paulo) de uma moção que defende a relevância dos acervos de museus universitários, cujos 
aportes financeiros vêm decaindo progressivamente junto ao orçamento de suas respectivas instituições.

O terceiro e último tópico, Ética e democracia para uma ciência cidadã, traz as reflexões de pesquisas mais atuais da área das tecnologias, especialmente aquelas que tangem inteligência artificial, justiça de dados, novas formas de comunicar a ciência e a diversidade de linguagens e suas tecnologias. Ricardo Abramovay (Universidade de São Paulo) salientou que é preciso que os museus tragam uma reflexão crítica e ética sobre $C \& T$, evitando uma visão apologética ou acrítica à revolução digital. A discussão perpassou a questão dos dados fornecidos por usuários de serviços digitais e seu uso desarticulado de uma agenda a serviço da sociedade, e como isso pode esbarrar em questões da dignidade humana na era digital.

Na mesma direção, a mesa-redonda sobre Agenda 2030, alicerçada no documento da ONU de 2015, reforçou a necessidade de se construir uma agenda na qual cultura e ciência sejam elementos centrais para um desenvolvimento sustentável. Sérgio Besserman (Jardim Botânico do Rio de Janeiro) apontou a urgência de se despertar no visitante coragem de ver o mundo com um olhar crítico, e que os museus, ao se relacionarem simbolicamente com as comunidades, precisam estar alinhados aos Objetivos de Deselvolvimento Sustentáveis (ODS), visando à formação cidadã, dando espaço para que os visitantes se tornarem curadores colaborativos desses espaços.

Uma das propostas para se mobilizar a atitude crítica das audiências de museus apareceu na mesa-redonda sobre controvérsias, que apresentou o potencial das exposições controversas para se trabalhar com temas políticos, sociais e culturais nos quais a ciência está imersa. Ana Maria Iannini (Toronto University) defendeu que dissenso e conflito são dimensões valiosas para provocar o visitante a refletir e tomar decisões diante de diferentes cenários. Contudo, podem criar barreiras internas e externas, devido à questões morais, de crença..., além de dificultar a já complexa tarefa de encontrar patrocínio.

Durante os seis dias de evento, foi possível perceber, por um lado, uma forte preocupação com os cenários futuros das instituições museológicas brasileiras e latino-americanas, especialmente no que se refere às políticas públicas ineficientes, o que levou a um claro posicionamento da ABCMC que aprovou moções relativas a: defesa das universidades públicas, especialmente a Universidade Federal do Rio de Janeiro (UFRJ) (atacada após a tragédia do Museu Nacional, visto que o museu está ligado a esta universidade); rechaço à proposta da Base Nacional Comum Curricular, que propõe um currículo unificado e limita a autonomia docente; apoio à inclusão de museus como espaços de formação docente inicial.

Por outro lado, a crescente presença das pesquisas empreendidas em estados com histórico de subdesenvolvimento e relativo atraso científico, despontando como produtores de conhecimento e interlocutores valiosos para o campo de estudos. Ademais, o grande número de jovens que participaram ativamente das atividades do Encontro, com posições firmes e reflexões lúcidas, traz otimismo frente ao turbulento momento da história que estamos atravessando. 
Lara Mucci Poenaru. Pesquisadora no Instituto Federal de Educação, Ciência e Tecnologia do Pará - IFPA (Belém, Brasil). Mestrada na Universidade Federal de Minas Gerais - UFMG (Minas Gerais, Brasil) e doutoranda na Universidade Federal do Pará - UFPA (Belém, Brasil). E-mail: laramuccipoenaru@gmail.com.

Como citar

Mucci Poenaru, L. (2018). 'Encontro Nacional da Associação Brasileira de Centros e Museus de Ciências (ABCMC)'. JCOM - América Latina 01 (01), R01. https://doi.org/10.22323/3.01011001.

(C) $\mathrm{O}(\mathrm{s})$ autor(es). Esta publicação é disponibilizada nos termos da licença Atribuição - Não Comercial — SemDerivações 4.0 da Creative Commons. Publicado pela SISSA Medialab. jcomal.sissa.it 